\title{
Screening of plant growth promoting rhizobacteria for the development of vegetable crops inoculants
}

\author{
Anelise Dias ${ }^{1 \star}$, Silvana Gomes dos Santos ${ }^{2}$, Vinicius Gomes da Silva Vasconcelos ${ }^{2}$, \\ Viviane Radl ${ }^{3}$, Gustavo Ribeiro Xavier ${ }^{1}$, Norma Gouvêa Rumjanek ${ }^{1}$ \\ and Raul de Lucena Duarte Ribeiro ${ }^{2}$ \\ ${ }^{1}$ Embrapa Agrobiologia, BR 465, Km 07, Seropédica, RJ, CEP 23890-000, Brazil. \\ ${ }^{2}$ Universidade Federal Rural do Rio de Janeiro - UFRRJ, BR 465, Km 07, Seropédica, RJ, CEP 23890-000, Brazil. \\ ${ }^{3}$ German Research Center for Environmental Health, Ingolstädter Landstr. 1, 85764 Neuherberg, Germany.
}

Accepted 25 March, 2013

\begin{abstract}
The enrichment of plant rhizosphere with beneficial bacteria is a strategy that favors the production of more vigorous seedlings, which is essential for the success of vegetable cultivation. The aim of this study was to screen fluorescent pseudomonads that are able to act as plant growth-promoting rhizobacteria. Production of indole acetic acid (IAA) and phosphate solubilization were used as traits for initial screening of 78 strains. In addition, we evaluated kale growth promoting ability under greenhouse conditions in unsterilized soil. Strains that significantly increased the dry mass of plants were characterized based on biochemical traits and by 16S rRNA sequencing. All isolates produced IAA. From these, 59 solubilized $\mathrm{CaHPO}_{4}$. Seven strains which promoted kale growth, presented low or intermediate solubilization efficiency and IAA production ability and were characterized as Pseudomonas putida. Seven growth promoting strains with potential for the development of inoculants were selected for future tests under field conditions. This study also shows that growth promoting capability was not consistently related in vitro to IAA production and phosphate solubilization.
\end{abstract}

Key words: Rhizospheric soil, auxin, phosphorus, kale, root colonization.

\section{INTRODUCTION}

Vegetables are well known as very important constituents of a healthy diet, especially because of their nutrition quality, including high content of mineral salts and vitamins, which have been showing benefits in the prevention of certain types of cancers, cardiovascular diseases, diabetes, among other illnesses (Poll et al., 2012). The horticulture is a growing sector of Brazilian agribusiness, corresponding to $12.4 \%$ of the gross domestic product, which amounts to $\$ 100$ billion (Poll et al., 2012). This has led to an increasing interest in the development of new approaches to improve Brazilian's vegetable production.

A strategy that has been often proposed is the enrichment of the rhizosphere with plant growth-promoting rhizobacteria (PGPR) (Lugtenberg and Kamilova, 2009).
The inoculation of PGPR on the seeds and substrate can favor the production of more vigorous seedlings due to the protection against soilborne plant pathogens, production of growth regulators, better use of fertilizers and induction of tolerance to environmental stresses (Compant et al., 2010; Glick, 2010).

Among PGPR, fluorescent pseudomonads are good rhizosphere colonizers, although they have also been found inside tissues of flowers and fruits (Compant et al., 2010; Peix et al., 2009) and, more recently, reported to induce the formation of root nodules in black locust (Shiraishi et al., 2010). A straightforward strategy to obtain PGPR is the screening of pseudomonads isolated from agro-ecological farms, which possess higher microbial diversity than observed under conventional manage- 
ment (Altieri, 1999). Besides, isolation from samples taken from the rhizosphere tends to provide bacterial strains that directly interact with plant roots. Fluorescent pseudomonads possess high rhizosphere competence and they are recognized as one of the main groups of PGPR or plant-probiotic bacteria (Höfte and Altier, 2010; Lugtenberg and Kamilova, 2009).

The ability to produce indole acetic acid (IAA) and to solubilize phosphate by pseudomonads is well correlated with the potential of these bacteria to promote growth of different plants in greenhouse and field experiments (Ahmed and Shahab, 2011; Spaepen and Vanderleyden, 2010). It has been suggested that IAA is involved in the communication between bacteria and in plant-bacteria interactions (Spaepen et al., 2007). Nevertheless, although about $80 \%$ of the rhizosphere inhabiting bacteria are IAA producer, the exact ecological role of IAA production remains unclear. Phosphate solubilization appears to be an advantageous mechanism for soil bacterial, due to the reduced availability of phosphorus in many soil environments. A great proportion of rhizosphere bacteria are able to solubilize $P$ in vitro, and such bacteria could be selected to develop inoculants to reduce $P$ deficiency in agriculture soils (Ahmed and Shahab, 2011).

Although these mechanisms have been abundantly recognized, little is known about the diversity and the potential of plant growth promoting pseudomonas of vegetable crops in tropical soils. In Brazil, where the use of bacteria as inoculants is legally restricted, there are no commercial products registered at Brazilian Ministry of Agriculture, Livestock and Food Supply containing fluorescent pseudomonads as an active ingredient (Brasil, 2012). However, strains belonging to Pseudomonas putida, Pseudomonas fluorescens and Pseudomonas chlororaphis are commercialized in the USA (Kiewnick, 2007) and Europe (Alabouvette et al., 2006). These bacteria represent a great opportunity to improve vegetable crops yield and to reduce economic and environmental costs with mineral fertilizers, as already demonstrated for soybean, cowpea and more recently, for sugarcane (Rumjanek et al., 2005; Silva et al., 2009). Therefore, in the present study, rhizobacteria isolated from vegetable crops cultivated under organic production system were screened for production of IAA, phosphate solubilization and growth promotion, using kale as indicative plant.

\section{MATERIALS AND METHODS}

\section{Origin of bacterial strains}

Seventy eight (78) isolates of fluorescent rhizobacteria were obtained from kale (Brassica oleacea var. acephala L.), lettuce (Lactuca sativa L.), parsley (Petroselinum sativum L.) and rudbeckia (Eruca sativa Miller) cultivated on an experimental area (SIPA - Integrated Agroecological Production System) located in Seropédica, lat $22^{\circ} 45^{\prime} \mathrm{S}$, long $43^{\circ} 41^{\prime} \mathrm{N}$ in Rio de Janeiro State, Brazil (Pinton et al., 2010). This area represents a collaborative research effort between Embrapa Agrobiologia, Universidade Federal Rural do Rio de Janeiro and Pesagro-Rio. Three plants of each vegetable species were harvested at the last third part of the vegetative cycle and the roots shaken to remove the loosely attached soil. The adhering soil of the three plants was pooled and considered as the rhizosphere soil. Rhizosphere soil $(1 \mathrm{~g})$ from each vegetable species was mixed with $9 \mathrm{ml}$ of distilled water and serial dilutions were prepared. One hundred microliters of each dilution were spread on plates containing King's B agar amended with the antibiotics as described by Pinton et al. (2010). Fluorescent colonies presenting growth characteristics of pseudomonad were isolated and stored in glycerol at $-80^{\circ} \mathrm{C}$ for further analysis.

\section{Production of IAA and IAA-related compounds}

The production of IAA and IAA related compounds was determined by spectrophotometry. Bacterial suspensions $\left(10^{9} \mathrm{CFU} \mathrm{ml^{-1 }} 0.85 \%\right.$ $\mathrm{NaCl}$ ) were inoculated in $5 \mathrm{ml}$ Tryptone Soy broth amended with $200 \mathrm{\mu g} \mathrm{ml}^{-1}$ L-tryptophan (Sigma-Aldrich, St Louis, USA). The samples were then incubated for $72 \mathrm{~h}$ at $29^{\circ} \mathrm{C}$ under agitation (150 $\mathrm{rpm}$ ) in the dark. Optical cell density (OD) was measured by spectrophotometer (absorbance at $600 \mathrm{~nm}$ ). A $1.5 \mathrm{ml}$ aliquot of the supernatant, obtained after centrifugation of the culture at 10,000 $\mathrm{rpm}$ for $5 \mathrm{~min}$, was mixed with $1 \mathrm{ml}$ of Salkowski's reagent that can react mainly with indole acetic acid, but also with indolepyruvic acid and indoleacetamide (Glickmann and Dessaux, 1995). After $30 \mathrm{~min}$ of incubation in the dark, absorbance was determined at $540 \mathrm{~nm}$. The concentration of IAA and IAA-related compounds was expressed in $\mu \mathrm{g} \mathrm{ml}^{-1}$ per unit $\mathrm{OD}$ (optical density) of the bacterial cultures, using a standard curve prepared with synthetic IAA (Sigma-Aldrich, St Louis, USA).

\section{Phosphate solubilization ability}

The isolates were tested using GY medium (Katznelson and Bose, 1959) containing $\mathrm{CaHPO}_{4}$ as sole phosphate source. After 12 days of incubation at $29^{\circ} \mathrm{C}$, the solubilization index (SI) was determined by dividing the halo diameter by the colony diameter (Berraquero et al., 1976). The SI was used to classify the strains in terms of solubilization efficiency (SE) as low $(\mathrm{SI}<2)$, intermediate $(2<\mathrm{SI}<3)$ or high (IS>3) (Hara and Oliveira, 2005).

\section{Inoculation of kale with PGPR under controlled conditions}

A total of 78 strains were evaluated in four experiments. From these, seven isolates (BR9130, BR9133, BR9128, BR9121, BR9132, BR9109 and BR9129) that increased biomass of inoculated plants higher than the control without inoculation were re-evaluated in a separate assay. The isolates were inoculated by

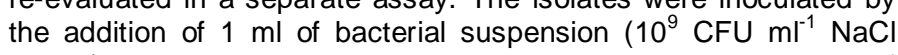
$0.85 \%$ ) on the soil surrounding kale roots in pots containing $1 \mathrm{~kg}$ of a non sterilized dystrophic sandy soil, with the following chemical characteristics: $\mathrm{pH}, 5.3 ; \mathrm{Al}, 0.3 \mathrm{cmolc} \mathrm{dm}^{-3} ; \mathrm{Ca}+\mathrm{Mg}, 0.9 \mathrm{cmolc} \mathrm{dm}$ 3; P, $4 \mathrm{mg} \mathrm{dm}^{-3}$; $\mathrm{K}, 20 \mathrm{mg} \mathrm{dm}^{-3}$; carbon, $0.33 \%$ and organic matter, $0.57 \%$. Ten days after sowing (DAS) controls received the same amount of sterile saline solution $(0.85 \% \mathrm{NaCl})$. Fifteen DAS, $6 \mathrm{ml}$ of nutrients solution containing (in $\mathrm{gL}^{-1}$ ) $\mathrm{NH}_{4} \mathrm{NO}_{3}(2.8), \mathrm{K}_{2} \mathrm{HPO}_{4}$ (3.5), $\mathrm{CaCl}_{2} .2 \mathrm{H}_{2} \mathrm{O}(10.5)$ and $\mathrm{MgSO}_{4} .7 \mathrm{H}_{2} \mathrm{O}(0.35)$ were added to each pot. The essay was maintained in a greenhouse at an average temperature of $27^{\circ} \mathrm{C}$ and plants were irrigated with $40 \mathrm{ml}$ of distilled water twice a day. The randomized blocks design was adopted, with five replicates. Dry weight of shoots and roots was determined.

\section{Biochemical characterization}

Isolates capable of promoting plant growth were biochemically 
Table 1. Class division of fluorescent vegetable rhizobacteria according to IAA like molecules production, phosphate solubilization and plant growth promoting.

\begin{tabular}{|c|c|c|c|c|}
\hline \multirow{3}{*}{$S^{a}$} & \multicolumn{4}{|c|}{$\mathrm{IAA}^{\mathrm{b}}$} \\
\hline & \multicolumn{4}{|c|}{ Classes ( $\mu \mathrm{g} \mathrm{ml}^{-1}$ per unit OD) ${ }^{\mathrm{b}}$} \\
\hline & Low & Medium & High & Total \\
\hline Null & $7(0)^{c}$ & $8(0)$ & $4(0)$ & $19(0)$ \\
\hline Low & $7(1)$ & $19(4)$ & $5(0)$ & $31(5)$ \\
\hline Intermediate & $8(0)$ & $12(2)$ & $4(0)$ & $24(2)$ \\
\hline High & $0(0)$ & $2(0)$ & $2(0)$ & $4(0)$ \\
\hline Total & $22(1)$ & $41(6)$ & 15 & $78(7)$ \\
\hline
\end{tabular}

a Solubilization efficiency: null = bacterium did not grow; low = solubilization index $(\mathrm{SI})<2$, intermediate $=2<\mathrm{SI}<3$ and high $=$ $\mathrm{SI} \geq 3$. ${ }^{\mathrm{b}}$ Production of indole acetic acid (IAA and IAA-related in culture medium supplemented with $200 \mathrm{~g} \mathrm{ml}^{-1}$ of tryptophan), expressed in $\mu \mathrm{g} \mathrm{ml^{-1 }}$ per optical cell density (unit OD, absorbance at $600 \mathrm{~nm}$ ). Isolates were classified as 'low' if $<18$ $\mu \mathrm{g} \mathrm{ml}^{-1}$ optical cell density per unit OD was detected, 'medium' for 18 to $42 \mu \mathrm{g} \mathrm{ml}^{-1}$ per unit OD and 'high' if it released $>42 \mu \mathrm{g}$ $\mathrm{ml}^{-1}$ per unit OD. ${ }^{c}$ Values between parentheses indicate the number of isolates in each class that increased the biomass of kale as shown.

characterized using the commercial Kit API system 20NE (BioMérieux Laboratory, France).

\section{S rRNA gene sequencing}

Total DNA from the isolates capable of promoting plant growth on kale was isolated using phenol chloroform extraction basically as described (Ausubel et al., 1992). 16S rRNA genes were amplified from $20 \mathrm{ng}$ of template DNA using the universal eubacterial primer set $27 \mathrm{f} / 1492 \mathrm{r}$ with an initial denaturation step at $95^{\circ} \mathrm{C}$ for $10 \mathrm{~min}$, followed by 30 cycles of $94^{\circ} \mathrm{C}$ for $1 \mathrm{~min}, 58^{\circ} \mathrm{C}$ for $1 \mathrm{~min}, 72^{\circ} \mathrm{C}$ for 2 min and a final extension at $72^{\circ} \mathrm{C}$ for 5 min. Reactions were performed in $50 \mu \mathrm{l}$ volume with the composition recommended by the manufacturer (Invitrogen, Brazil). Amplicons were purified using the Qiaquick PCR purification kit (Qiagen, Germany). Sequencing reactions were carried out in a $3730 \mathrm{ABI} D N A$ Analyzer using the BigDye terminator 3.1 sequencing kit (Applied Biosystems, USA). Sequences were compared with the GenBank database (http://www.ncbi.nih.gov) using BLAST (Altschul et al., 1997) and aligned using Clustal W (EMBL-EBI, http://www.ebi.ac.uk/clustalw/). Neighbor-joining (NJ) analyses were performed with MEGA 4 (Tamura et al., 2007), using the Kimura-2 correction and 5000 bootstrap replicates.

\section{Data analysis}

The data were subjected to analysis of variance (ANOVA) and the Scott-Knott test at the 0.05 significance level.

\section{RESULTS}

\section{Growth promotion tests}

All isolates produced IAA and IAA-related compounds in vitro. The amount produced varied from 0.78 to $401.62 \mu \mathrm{g}$ $\mathrm{ml}^{-1}$ per unit OD. Based on the amount of IAA produced, isolates were grouped as 'low' for values below $18 \mathrm{\mu g} \mathrm{ml}^{-1}$ per unit OD, 'intermediate' for values ranging from 18 to $42 \mu \mathrm{g} \mathrm{ml}^{-1}$ per unit OD and 'high' for values higher than $42 \mu \mathrm{g} \mathrm{ml}^{-1}$ per unit OD (Table 1). Most of the isolates $(52.56 \%)$ were classified as intermediate producers and $19.23 \%$ produced high amounts of IAA. From all the isolates, $75.6 \%$ solubilized $\mathrm{CaHPO}_{4}$. From those, $39.74 \%$ showed low, $30.76 \%$ showed intermediate and $5.13 \%$ showed high efficiency of solubilization. In the greenhouse experiments, seven out of the 78 isolates showed a positive effect on plant growth and inoculated plants presented higher shoot and root dry weight than the control (Table 2). Depending on the isolate tested, the increase in shoot growth ranged from 79.80 to $131.60 \%$. Although the plant growth promoting ability of the strains did not differ significantly, the highest increase on shoot dry weight was observed for the strain BR9109. The effect on root growth appeared to be more pronounced. Increases ranging from 106.80 to $221.10 \%$ were observed after inoculation with the different effective isolates $(p \leq 0.05)$. Plants inoculated with the strain BR9129 showed the highest values of root dry mass and total dry mass.

\section{Biochemical characterization}

As determined by the API system, all seven PGPR strains presented a biochemical profile identical to $P$. putida. All strains produced fluorescent pigments, showed positive reaction for arginine dihydrolase, assimilation of glucose, potassium gluconate, malate and trisodium citrate and negative to gelatin hydrolysis, glucose fermentation, urease activity and assimilation of mannitol and adipic acid.

\section{Phylogenetic analysis}

The results of comparative analysis of the 16S rRNA gene sequence of the seven isolates was not conclusive, although the identification of API 20NE was confirmed to genus level. Strains are very closely related to $P$. putida, Pseudomonas plecoglossicida, Pseudomonas fulva and Pseudomonas monteilii sequences from the database (Figure 1).

\section{DISCUSSION}

The aim of this study was to isolate and characterize fluorescent pseudomonads that are able to promote growth of vegetable crops. Therefore, the strategy was to isolate bacteria from the rhizosphere of the target plant species: kale, lettuce, parsley and rudbeckia grown under organic management, as a starting point in the selection 
Table 2. Plant growth promoting rhizobacteria characterized by IAA and IAA-related compounds production and solubilization of calcium monophosphate.

\begin{tabular}{lccccc}
\hline \multirow{2}{*}{ Treatment } & \multicolumn{3}{c}{ Growth promotion $^{\mathrm{a}}$} & \multicolumn{1}{c}{ IAA $^{\mathrm{b}}$} & Phosphate solubilization $^{\mathrm{c}}$ \\
\cline { 2 - 6 } & SDW $(\mathbf{g})$ & RDW $(\mathbf{g})$ & TDW $(\mathbf{g})$ & ug m $^{-1}$ unitOD $^{-1}$ & SI \\
\hline Control & $0.39^{\mathrm{b}}$ & $0.27^{\mathrm{b}}$ & $0.65^{\mathrm{c}}$ & - & - \\
BR9130 & $0.69^{\mathrm{a}}$ & $0.41^{\mathrm{b}}$ & $1.11^{\mathrm{b}}$ & $7.22^{\mathrm{c}}$ & $1.79^{\mathrm{b}}$ \\
BR9133 & $0.81^{\mathrm{a}}$ & $0.55^{\mathrm{a}}$ & $1.36^{\mathrm{a}}$ & $32.68^{\mathrm{b}}$ & $1.62^{\mathrm{b}}$ \\
BR9128 & $0.80^{\mathrm{a}}$ & $0.62^{\mathrm{a}}$ & $1.42^{\mathrm{a}}$ & $41.74^{\mathrm{a}}$ & $1.87^{\mathrm{b}}$ \\
BR9121 & $0.80^{\mathrm{a}}$ & $0.68^{\mathrm{a}}$ & $1.49^{\mathrm{a}}$ & $27.03^{\mathrm{b}}$ & $2.23^{\mathrm{a}}$ \\
BR9132 & $0.86^{\mathrm{a}}$ & $0.60^{\mathrm{a}}$ & $1.47^{\mathrm{a}}$ & $40.01^{\mathrm{a}}$ & $1.96^{\mathrm{b}}$ \\
BR9109 & $0.89^{\mathrm{a}}$ & $0.72^{\mathrm{a}}$ & $1.62^{\mathrm{a}}$ & $23.34^{\mathrm{b}}$ & $2.31^{\mathrm{a}}$ \\
BR9129 & $0.82^{\mathrm{a}}$ & $0.85^{\mathrm{a}}$ & $1.67^{\mathrm{a}}$ & $24.73^{\mathrm{b}}$ & $1.76^{\mathrm{b}}$ \\
VC(\%) $^{\mathrm{d}}$ & 24.88 & 33.73 & 24.29 & 9.4 & 11.9 \\
\hline
\end{tabular}

Values within a column followed by a same letter are not significantly different according to Scott-Knott test $(P<0.05) .{ }^{a} G r o w t h$ promoting kale (Brassica oleracea cv. acephala) under greenhouse conditions. Evaluated parameters were shoot dry weight (SDW), root dry weigtht (RDW) and total dry weight (TDW). ${ }^{\text {b }}$ Production of indole acetic acid (IAA and IAA-related in culture medium supplemented with $200 \mathrm{\mu g} \mathrm{ml}^{-1}$ of tryptophan), expressed in $\mu \mathrm{g} \mathrm{m}{ }^{-1}$ per optical cell density (unit OD, absorbance at $600 \mathrm{~nm}$ ). ${ }^{\circ}$ Index of solubilization (SI) of $\mathrm{CaHPO}_{4}$. ${ }^{\mathrm{V}}$ Variation coefficient.

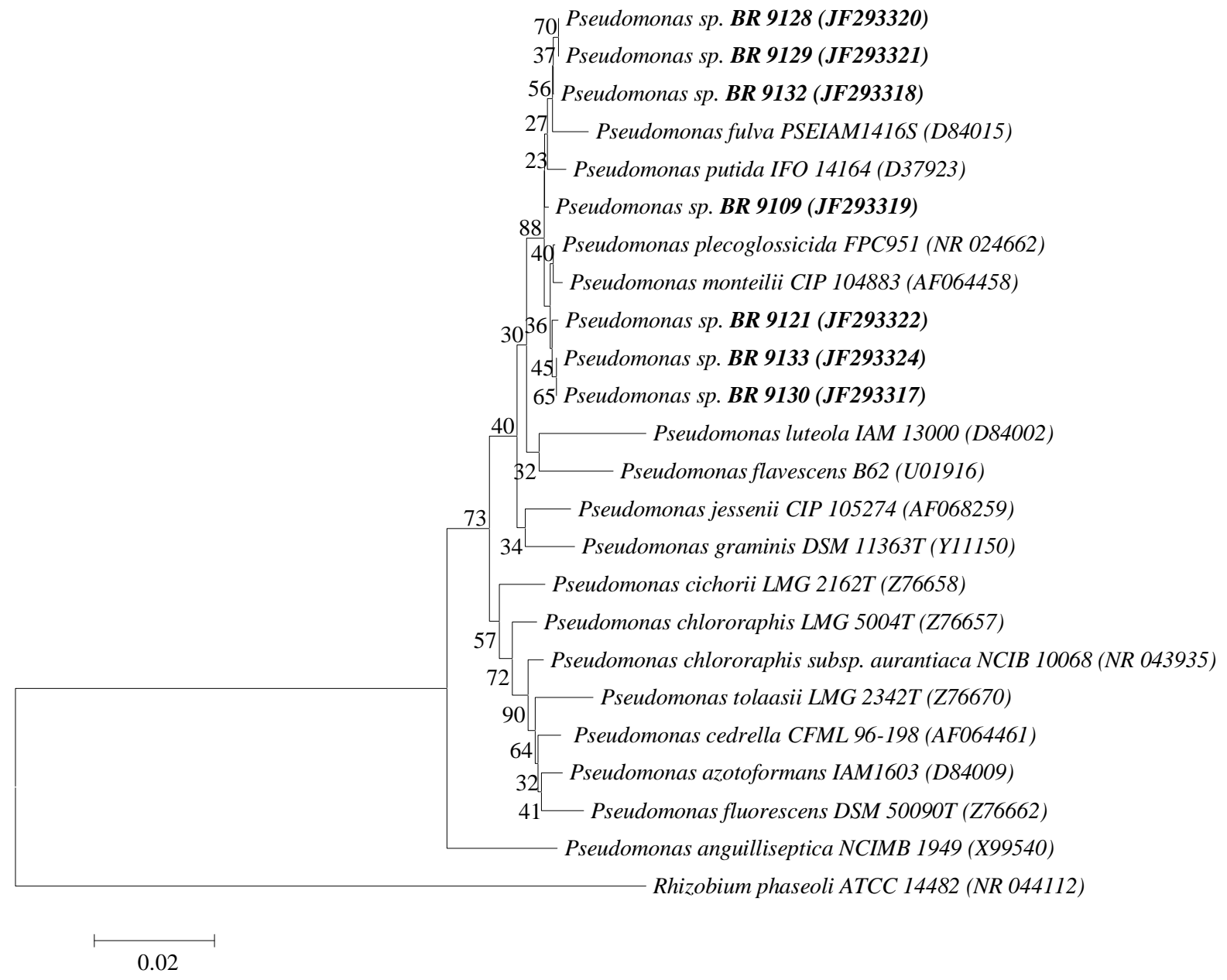

Figure 1. Phylogenetic tree based on 16S rRNA gene sequences of Pseudomonas spp. The tree was generated by the neighbor-joining method. Numbers at nodes indicate bootstrap values (percentage of 5000 replicates). Scale bar: 0.02 substitutions per nucleotide position. Name of each type strain and/or isolate follows the sequence accession numbers. 
of PGPR. We started by evaluating IAA production and phosphate solubilization as initial traits for strain selection, as these are recognized as traits of efficient PGPRs (Compant et al., 2010; Lugtenberg and Kamilova, 2009).

IAA production is more frequent among rhizosphere inhabiting bacteria than among bulk soil bacteria (Spaepen and Vanderleyden, 2011). Accordingly, in the present study, all isolates obtained from the vegetable rhizosphere produced IAA. Therefore, it seems likely that the IAA production by these isolates has a role in rhizosphere colonization, as has been suggested by Spaepen et al. (2007).

In general, the capacity to solubilize calcium phosphate by rhizobacteria is linked to type and quantity of organic acid production (Rodriguez and Fraga, 1999) and we suppose that this may explain the predominance of low and average efficiency of solubilization found among the isolates studied.

Total dry weight was higher in plants inoculated with seven out of the 78 isolates. All the plant growth promoters produced IAA and solubilized phosphate. These isolates differ significantly in the production of IAA and also in the SE, but there is no clear relationship between the amounts of IAA and $P$ solubilization to their contribution to plant growth promotion. Besides these, it is possible that others, as yet not investigated mechanisms are responsible for the effect of these strains on plant growth. Furthermore, metabolites synthesis by bacteria in the rhizosphere depends on precursors present in root exudates that vary among plant species, growth phase and day/night periodicity of exudation.

Our results showed that a screening method based on these traits considering the activity of the bacteria in vitro might not to be a good approach to select PGPR, as this does not necessarily indicate its effects on the plant growth under greenhouse conditions, especially in nonsterile soils, suggesting a sensitivity to critical factors, such as establishment in the roots, competition with resident microbiota and survival under abiotic stresses. Smyth and co-workers (2011) studied rhizobacteria from cereals and found similar results. There was no significant correlation between wheat growth promotion in the glasshouse and the results of phenotypic tests. Furthermore, other mechanisms that were not investigated in this study may also be involved in the response of increased growth of plant such as nitrogen fixation, production of siderophores, exopolissacarides and ACC deaminase enzyme (Glick et al., 2007; Compant et al., 2010).

Although, the screening of plant performance in nonsterile soil does not reveal all the mechanisms involved, from a practical point of view, this is more recommended than in vitro methods as discussed by Pliego et al. (2011). Possibly for that reason, only $9 \%$ of the isolates evaluated in this study promoted plant growth under non- sterile soil conditions despite displaying favorable traits under in vitro conditions. Experimental conditions using non-sterile soil stimulate competition of the selected bacteria with resident microorganisms and the need to survive under abiotic stress in the soil.

In our study, we observed that the seven strains that promoted the growth of kale, showed low and medium production of IAA. These data are in accordance with results of Jayasudha et al. (2010) that showed that the growth of groundnut plants was not greatly influenced by fluorescent pseudomonads that produced high amounts of IAA, but by lower and medium producers of it.

In this study, the effect on the growth of kale by PGPR occurred mainly in the root system. The increase of the root system is advantageous for seedlings of vegetables because may dock them faster on the ground, promote the achievement of water and nutrients, increasing their chances of survival (Ahmed and Shahab, 2011). The IAA produced by bacteria can change the pool of plant auxin stimulating the emergence of lateral roots that allow plants to better explore the soil, which in turn may lead to improve access to water and minerals. This can favor the uptake by plants, phosphorus which comes into contact with the roots through radicular interception (Ali et al., 2010; Hodge et al., 2009). It may in turn lead to further increases of the shoot mass, leading to greater rates of photosynthesis, more exudation and more niches in the rhizosphere.

As expected, all PGPR strains belonged to the genus Pseudomonas, as shown by the API and 16S rRNA gene sequence analysis. They were grouped in the rRNA group I, which is the genus Pseudomonas sensu stricto (Palleroni, 1984), with the following examples, fluorescence production, assimilation of glucose and negative to glucose fermentation. All the PGPR strains had biochemical profiles identical to $P$. putida, which shows negative reaction to gelatin hydrolysis, normally used to differentiate them from $P$. fluorescens, Pseudomonas clororaphis, Pseudomonas aureophaciens and Pseudomonas aeruginosa that belonged to the same homology group.

In the present study, we selected seven Pseudomonas strains that promoted the growth of kale plants under greenhouse conditions, showing a great biotechnological potential. Moreover, pre-selections using in vitro tests of some commonly used traits, such as phosphate solubilization and IAA production may mask actual PGPR strains.

\section{ACKNOWLEDGEMENTS}

We gratefully acknowledge the Universidade Federal Rural do Rio de Janeiro and Embrapa, Conselho Nacional de Pesquisa e Desenvolvimento, Fundação de Apoio à Pesquisa do Estado do Rio de Janeiro and as well Coordenação de Aperfeiçoamento de Pessoal de 
Nível Superior for the financial support and scholarships granted. We also thank Dr. Luc F. M. Rouws for review of this text.

\section{REFERENCES}

Ahmed N, Shahab S (2011). Phosphate solubilization: their mechanism genetics and application. Internet J. Microbiol. http://www.ispub.com/journal/the-internet-journal-ofmicrobiology/volume-9-number-1/phosphate-solubilization-theirmechanism-genetics-and-application.html. Acessed 04 January 2011.

Alabouvette C, Olivain C, Steinberg C (2006). Biological control of plant diseases: The European situation. Eur. J. Plant Pathol. 114: 329-341.

Ali B, Sabri A, Hasnain S (2010). Rhizobacterial potential to alter auxin content and growth of Vigna radiata (L.). World J. Microbiol. Biotechnol. 26:1379-1384.

Altieri MA (1999). The ecological role of biodiversity in agroecosystems. Agroecosyst. Environ. 74:19-31.

Altschul SF, Madden TL, Schäffer AA, Zhang J, Zhang Z, Millar W, Lipman DJ (1997). Gapped BLAST and PSIBLAST: a new generation of protein database search programs. Nucleic Acid Res. 25:33893402.

Ausubel FM, Brent R, Kingston RE, Moore DD, Seidman JG, Smith JA, Struhl K (1992). Current protocols in molecular biology. WileyInterscience, New York, USA.

Berraquero FR, Baya AM, Cormenzana, AR (1976). Establecimiento de indices para el estudio de la solubilizacion de fosfatos por bacterias del suelo. Ars. Pharm. 17:399-406.

Brasil (2012). Phytosanitary pesticides system of the Ministry of Agriculture.

http://agrofit.agricultura.gov.br/primeira_pagina/extranet/AGROFIT. html. Accessed 04 October 2012.

Compant S, Clément C, Sessitsch A (2010). Plant growth-promoting bacteria in the rhizo- and endosphere of plants: Their role, colonization, mechanisms involved and prospects for utilization. Soil Biol. Biochem. 42:669-678.

Glick BR (2010). Using soil bacteria to facilitate phytoremediation. Biotechnol. Adv. 28:367-374.

Glickmann E, Dessaux YA (1995). Critical examination of the specificity of the Salkowski reagent for indolic compounds produced by phytopathogenic bacteria. Appl. Environ. Microbiol. 61: 793-796.

Hara FAS, Oliveira LA (2005). Physiological and ecological characteristics of rhizobia isolates from acid soils of Iranduba, Amazonas. Pesqui. Agropecu. Bras. 40:667-672.

Hodge A, Berta G, Doussan C, Merchan F and Crespi M (2009). Plant root growth, architecture and function. Plant Soil 321: 153-187.

Höfte M, Altier N (2010). Fluorescent pseudomonads as biocontrol agents for sustainable agricultural systems. Res. Microbiol. 161:464471.

Jayasudha T, Rangeshwaran R, Vajid NV (2010). Relationship between indole acetic acid production by fluorescent Pseudomonas and plant growth promotion. J. Biol. Control 24:349-359.

Katznelson H, Bose B (1959) Metabolic activity and phosphatedissolving capability of bacterial isolates from wheat root, rhizosphere and non-rhizosphere soil. Can. J. Microbiol. 5:79-85.

Kiewnick S (2007). Practicalities of developing and registering microbial biological control agents. CAB Rev. Pers Agr Vet. Sci. Nut Nat Res. 2(13):1-11.

Lugtenberg B, Kamilova F (2009). Plant-growth-promoting rhizobacteria. Annu. Rev. Microbiol. 63: 541-556.
Palleroni NJ (1984). Genus I. Pseudomonas migula. In: Manual of Systematic Bacteriology. Krieg NR, Holt JG (eds). Williams \& Wilkins. Baltimore. pp. 141-199.

Peix A, Ramirez-Bahena MH, Velazquez E (2009). Historical evolution and current status of the taxonomy of genus Pseudomonas. Infect. Genet. Evol. 9:1132-1147.

Pinton R, Dias A, Xavier TF, Rouws LFM, Xavier GR, Rumjanek NG, Ribeiro RLD (2010). Morphocultural characterization, autoinducer biosynthesis and biofilm formation in rhizobacteria isolated from vegetable crops. Pesqui. Agropecu. Bras. 45:284-293.

Pliego C, Ramos C, de Vicente A, Cazorla F (2011). Screening for candidate bacterial biocontrol agents against soilborne fungal plant pathogens. Plant Soil 340:505-520.

Poll H, Vencato AZ, Kist BB, Carvalho C, Reetz ER, Beling RR (2012). Brazilian vegetable yearbook. Gazeta Santa Cruz. Santa Cruz do Sul. pp. 12-15.

Rodriguez H, Fraga R (1999). Phosphate solubilizing bacteria and their role in plant growth promotion. Biotechnol. Adv. 17:319-339.

Rumjanek NG, Martins LMV, Xavier GR, Neves MCP (2005). Biological nitrogen fixation. In: Cowpea bean: technological advances. Freire Filho FR, Lima, JAA, Ribeiro, VQ (eds). Embrapa Informação Tecnológica. Brasília. pp. 281-335.

Shiraishi A, Matsushita N and Hougetsu T (2010). Nodulation in black locust by the Gammaproteobacteria Pseudomonas sp. and the Betaproteobacteria Burkholderia sp. Syst. Appl. Microbiol. 33:269274.

Silva MF, Oliveira PJ, Xavier GR, Rumjanek NG, Reis VM (2009). Inoculants containing polymers and endophytic bacteria for the sugarcane crop. Pesqui. Agropecu. Bras. 44:1437-1443.

Smyth EM, McCarthy J, Nevin R, Khan MR, Dow JM, O'Gara F, Doohan FM (2011). In vitro analyses are not reliable predictors of the plant growth promotion capability of bacteria; a Pseudomonas fluorescens strain that promotes the growth and yield of wheat. J. Appl. Microbiol. 111:683-692.

Spaepen S, Vanderleyden J (2011). Auxin and plant-microbe interactions. Cold Spring Harbor Perspect. Biol. 3: a001438.

Spaepen S, Vanderleyden J, Remans R (2007). Indole-3-acetic acid in microbial and microorganism-plant signaling. FEMS Microbiol. Rev. 31:425-448.

Tamura K, Dudley J, Nei M, Kumar S (2007). MEGA4: Molecular Evolutionary Genetics Analysis (MEGA) software version 4.0. Mol. Biol. Evol. 24:1596-1599. 